\title{
IMPACT OF TELEVISION ADVERTISEMENTS ON YOUTH BUYING BEHAVIOR: WITH SPECIAL REFERENCE TO FRUIT DRINK MARKET IN SRI LANKA
}

\author{
Weerasiri, R.A.S ${ }^{1}$ and Nadeeka, H.S ${ }^{2}$ \\ ${ }^{1,2}$ Department Marketing Management, Faculty of Commerce \& Management Studies, University of Kelaniya, \\ Sri Lanka
}

\begin{abstract}
This study aims to establish whether the effects of Television advertisement influences today's youth for buying decisions for fruit drink market in Sri Lanka. A television advertisement has enhanced their involvement in product selection and purchase, people prefer to buy TV advertised products and helpful in buying the new products. Today competition of the fruit drink market is increasing rapidly and compared to the competition industry growth. Therefore the study was conducted on youth males and females between 18-25 of age group who are studied in University of Kelaniya, Youth segment in Kiribathgoda and working crowd at Maradana area. Data was collected through pre structured questionnaire and analyzed by using descriptive and inferential techniques with the help of SPSS 20.0 software. According to the findings, the youth of Sri Lanka always not believe that products are as good as demonstrated in TV advertisements. And also they are expecting to buy fruit drinks after watching Television Advertisements up to some extent. People believe that they can aware of new products; existing products and they can expand their knowledge by watching Television Advertisements. Youth segment think that using celebrity is a good way to remember the product name, to create positive attitude but they do not believe always it will not be true. To attract the youth segment Television Advertisement should be attractive and for that can use beautiful sceneries, interesting letters and attractive people.
\end{abstract}

Keywords: buying behavior, television advertisements, youth.

\section{INTRODUCTION}

In the soft drink market, there are lots of products available such as carbonated drinks, noncarbonated drinks and fruit drinks. In the sense carbonated drinks are the leading products. Now days though the need of fruit juices is increasing the demand for fruit drinks is slowly moving in the world as well as Sri Lanka. A reason for that is fruit juices are healthier than other carbonated drinks but the message has not clearly communicated. Before introduce the fruit drinks soft drinks were common for all the individuals. But after introducing fruit drinks, with the changing lifestyle and income levels, people are shifting their consumption patterns and therefore become more health conscious thus leading to

Corresponding Author Email: sudathweerasiri@ hotmail.com increase in demand of fruit drinks. Now there is a huge competition between fruit drinks and other carbonated drinks. There are so many brands have come to the market. With those many brands customer will stuck when they are purchasing products. They have to compare quality, price and features. In order to be successful in the marketplace, one has to think in terms of health innovation, flavor innovation, ingredient innovation and specific age groups. Therefore awareness of the brand is must in this competitive environment. To increase the awareness of new products and existing products Television Advertisements are heavily used by current businesses.

Out of the population of 22.3 million in Sri Lanka most of the population lies under 35 years of age. So, Sri Lanka has more youth generation. They are 
more like to maintain their health. This young group can be heavily influenced by Television Advertisements. Therefore the advertising field has turned into youth generation from the elders and family. And also according to previous information with the increasing of employment of youth segment marketers have got new potential buyers to target. This youth segment is more open to new products, innovations and trends influenced by the advertising world.

But when it comes to Sri Lankan market the ethics plays major role for advertising. Since Sri Lanka is Buddhist country there are some cultural differentiations when comparing to other countries. Therefore the impact of television advertisements for fruit drink market is very crucial thing to think for the marketers.

\section{RESEARCH PROBLEM}

With the huge competition in the industry there is a major challenge for the marketers to identify the factors affecting on customer buying behavior. And also the advertisements are playing major role when influence customer buying behavior. Therefore it is clear that to change and influence youth segments buying behavior towards fruit drinks, advertisements are more important and useful. In this research the researcher tries to find how the fruit drink manufacturers use advertisements to influence buying behavior on youth segment. The problem here is how to use advertisements effectively to influence buying behavior of youth segment favorably on fruit drink market to increase the market share. Accordingly, this study was focused on "How far TV advertisements impact on Youth buying behavior of fruit juice market in Sri Lanka”.

\section{TELEVISION ADVERTISING AND CONSUMER BEHAVIOR}

Consumer behavior refers to the behavior that consumers display in searching for, purchasing, using, evaluating and disposing of products and services that would satisfy their needs (Schiffman \& Kanuk, 1996). Their buying behavior is influenced by various economic factors like the price of a product, family income, size of the family, disposable personal income and various non-economic factors like age, education, occupation, personality, life style, area of residence etc. Consumers consist of children, teenagers, adults and aged people. Almost every child and teenager in Sri Lanka is a regular viewer of television. They spend most of their free time in front of television watching programs/channels of their choice. They also watch family programs along with other family members during peak time i.e. from $7 \mathrm{pm}$ to $10 \mathrm{pm}$ and during weekends and on holidays.

Television Advertisement is generally considered the most effective mass market advertising and this is reflected by the high prices television networks charge for advertising airtime during popular television events (McLuhan, 1964). Although television advertising has been found to have great influence on consumer behavior, many people still deny being influenced by advertisements. However, Levis (1995) found that individuals who deny being influenced by advertisements unconsciously bought widely television advertised products. Advertisers through television can reach a whole spectrum of consumers.

Youths are now more knowledgeable. They are truly get their news and information primarily from television. The television medium is the most attractive and important place to advertise (Liebeck, 1998). By watching television, youths may gain information about products, brands, stores and shopping as well as information about as to how products are used and fit with certain lifestyle (Moschis, 1980).

Advertising to the youth is a delicate issue. Because of the combination of color, sound and action, television attracts more viewers than any other medium. Soft drinks companies focus their attention and advertising budgets on the youth market, through sponsorship of music events and link-ups with the most attractive and popular movie stars, pop singers and sports celebrities. Together, Pepsi and Coca-Cola spend INR 11,000 crores on advertising in a single year (Nawathe, Gawande, Dethe). The use of celebrities in order to increase the sales and/ or the recall value of a brand is very much important. The people watch films as their source of entertainment and watch sports also. 
Cricket and Movies are very popular in Sri Lanka. Celebrities which might be cricket stars like Kumar Sangakkara, Mahela Jayawardena and Anjelo Mathews or film stars like Shah Rukh Khan , Ranbir Kapoor or Katrina Kaif . The people treat them and believe them like what these celebrities wear, the way they talk, their statements and style of fashion. Marketers use this very preposition so as to influence their target customers may exist or potential ones. Celebrity endorsement can play a vital leading role when it comes to leading the public's decisions, in a market which has a vast number of local, regional, and international brands. However, a study by Sharma (2007) finds that nowadays consumer is not easily swayed by a celebrity in an advertisement but he needs full fledge information about the product also, followed by brand name, overall appeal, and music/ jingle. Advertisements being endorsed by celebrities are found to be less attractive and that the use of celebrities may not change the buying behavior of consumers significantly.

\section{CONCEPTUAL MODEL AND HYPOTHESES}

According to the theoretical findings, the following framework is constructed by including the factors which influence on buying behavior of youth in fruit drink market in Sri Lanka. In conceptualizing the study, researcher attempted to build up relationship between key variables in which four factors impact to buying behavior are taken as independent variables and buying behavior as dependent variable. According to the previous researches and articles based on foreign context, researcher has recognized that information given by the advertisements, using celebrity in advertisement, using jingles/Music and time belt are the main variables for buying behavior at television advertisements in fruit drink market. Going through this researcher has identified four variables such as information, celebrity endorsement, music/jingles, and attractiveness of the advertisement. This would enable the researchers to interpret the findings in a more comprehensive manner. The conceptual model that has been developed indicating their relationship is given below.

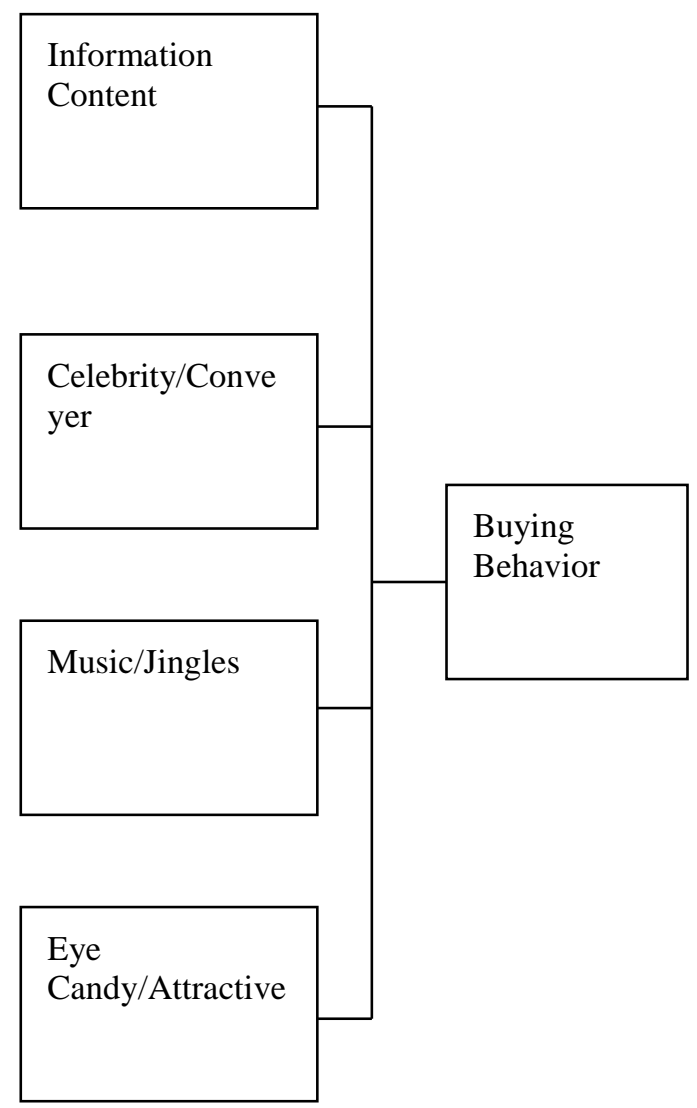

Figure 1: Conceptual Framework 


\section{HYPOTHESES}

In the hypotheses development, researcher has identified four hypotheses based on the selected variables.

H1: There is a significant relationship between Information Content of the Television advertisement and buying behavior of youth segment.

H2: There is a significant relationship between using celebrity/conveyer and buying behavior of youth segment.

H3: There is a significant relationship between using Music/jingles to Television advertisement and its impact of buying behavior of youth segment.

H4: There is a significant relationship between Eye candy/attractiveness of the Television advertisement and buying behavior of youth segment.

\section{METHODOLOGY}

The research methodology is based on both qualitative and quantitative techniques in data collection. But this research is more focusing on quantitative technique. In this study the researcher has gathered both primary and secondary data in order to identify the impact of Television Advertisements on youth buying behavior towards fruit drink in Sri Lanka. The main instrument to collect data was a research questionnaire. Through that can identify and understand the relationship between independent variables and dependent variable (cause and effect relationship). The Questionnaire prepared and filled through the selected sample size from the selected field. The Secondary data were collected from different magazines and newspapers. For the Literature of review certain online journals has also been collected. The sampling technique used in the sample design process is the convenience sampling which is one of the non-probability sampling techniques in which the population elements were selected. The target population is the youth generation among the age of 18-25. Data collection has been done from the sample size 200 of young girls and boys of University of Kelaniya, Maradana and Kiribathgoda area.
To analyze the collected data the researcher used correlation analysis. For that purpose SPSS 20.0 software has been used. The responses were entered by using different values and then analyzed as needed. The normal distribution was used to test the hypothesis, based on the results the hypothesis were rejected or accepted.

\section{DATA ANALYSIS AND RESULTS}

Table 1:Reliability Analysis

\begin{tabular}{lcc}
\hline Scale & $\begin{array}{l}\text { No. } \\
\text { of } \\
\text { items }\end{array}$ & $\begin{array}{l}\text { Cronbach's } \\
\text { Alpha }\end{array}$ \\
\hline $\begin{array}{l}\text { Information } \\
\text { Content } \\
\text { Celebrity/Conveyer }\end{array}$ & 04 & 0.739 \\
Jingles/Sounds & 04 & 0.684 \\
Eye Candy & 04 & 0.731 \\
Buying Behavior & 03 & 0.809 \\
\hline \multicolumn{1}{c}{ Source: Survey Data (2015) }
\end{tabular}

In order to determine the internal consistency researcher has tested the reliability. According to that the alpha coefficient for the four items in Information Content is 0.739 , suggesting that the items are highly reliable. The alpha coefficient of 0.684 of the four items in the Celebrity/Conveyer is suggesting that the items are probably reliable and have relatively good internal consistency. And also for the scale of Jingles/Sounds alpha coefficient is at 0.731 shows that the items are highly reliable. For the items in the Eye Candy, the alpha coefficient shows a figure of 0.809 suggesting that the items have relatively high internal consistency. The alpha coefficient for the three items in Buying Behavior is .817 , suggesting that the items are highly reliable. 
Table 2: Descriptive Statistics

\begin{tabular}{ll}
\hline Factor & Mean \\
\hline Buying Behavior & 3.12 \\
\hline Information Content & 3.77 \\
\hline Celebrity/Conveyer & 3.22 \\
\hline Music/Jingle & 3.79 \\
\hline Eye Candy/Attractiveness & 3.89
\end{tabular}

Source: Survey Data (2015)

The mean values of each variables were more than 3 which represents all the statements were accepted or respondents were agreed with the statements.

Table 3: Correlation Analysis

\begin{tabular}{llll}
\hline $\begin{array}{l}\text { Independent } \\
\text { Variable }\end{array}$ & $\begin{array}{l}\text { Dependent } \\
\text { Variable }\end{array}$ & Correlation Value & Significant Level \\
\hline Information Content & Youth Buying & $.432^{* *}$ & .000 \\
\cline { 4 - 4 } Celebrity/Conveyer & Behavior & $.445^{* *}$ & .000 \\
\cline { 1 - 1 } Music/Jingle & & $.462^{* *}$ & .000 \\
\cline { 3 - 4 } Eye Candy/Attractiveness & & $.337^{* *}$ & .000 \\
\hline
\end{tabular}

**. Correlation is significant at the 0.01 level (1-tailed).

Source: Survey Data (2015)

According to above table, all variable's Pearson correlation value takes less than the 0.5 and more than the 0 . Therefore it implies a significant relationship. And also hypothesis can be accepted at a significant level of 0.01 , as there is a positive relationship between Television Advertisements and youth buying behavior.

\section{DISCUSSION OF FINDINGS}

\section{Demographic Factors}

The sample consisted with both male and female equally in which 134 respondents were undergraduates and $54.5 \%$ of the sample was below Rs. 10,000 income earners. In addition to that $46 \%$ of the respondents are employed in private sector and $42.5 \%$ of the respondents are students.

\section{General Information}

Considering the general behavior of respondents almost all the respondents are watching television and also television advertisements. When looking at the viewing time of the television majority of the respondents have time to watch television in the night and they have 1-2 hours to watch television per day.
When considering whether TV Advertisements have made urgency to buy the product, nearly $80 \%$ respondents have stated that TV Advertisements are creating urgency to buy the products. It is a special point to care for the marketers.

When looking at the consumption of fruit drinks currently available in the Sri Lankan market $86.5 \%$ of the respondents are purchasing fruit drinks currently available in the market. When considering the satisfaction about current fruit drink TV Advertisements moderately respondents are satisfied with the current TV Advertisements because 52\% of respondents are satisfied with the TV Advertisements while $48 \%$ are dissatisfied. $29 \%$ of the respondents have purchased Minute Maid fruit drink just by attracted to the Television Advertisement. But $42 \%$ of the respondents have not purchased any fruit drink product just by attracted to the TV Advertisement.

\section{Information Content}

It has revealed that majority of the respondents believe of information on Television Advertisements and they strongly agree with that they can aware about existing products or new products in the market through TV Advertisements. And also the information of products on TV Advertisements can 
easily understand and through that can get the knowledge regarding many aspects.

\section{Celebrity/Conveyer}

As per the analysis of Celebrity/Conveyer, it has discovered that consumers have not a tendency to buy products or even trust the product is good when there is a celebrity appears in Television Advertisement. But they believe using a celebrity helps to create positive attitude regarding the product as well as can remember the product name in their mind.

\section{Jingles/Sounds}

It has revealed that majority of the respondents pay their attention to TV Advertisement when they hear Jingles or sound and also can remember the product easily with the Jingles or Sounds. And also reasonable amount of respondents can feel the product when they hear the Jingle or Sound as well as the jingle or sound can change the mood of them.

\section{Eye Candy/Attractiveness}

Majority of the respondents like to watch attractive Television Advertisements. When it has used attractive words and letters, bright colors, beautiful sceneries and beautiful persons they like to watch Television Advertisements.

This study has further revealed that using Jingles or Music and Celebrity or Conveyer impact much more to the Buying behavior of youth segment. Although Information Content of the Television Advertisement impacts directly to Buying Behavior of youth segment. Compared to other factors Eye Candy/Attractiveness of the TV Advertisement impact in a low level to the Buying Behavior. This study implies that there is a positive relationship between Television Advertisement aspects and Buying Behavior of youth segment towards the fruit drinks.

\section{CONCLUSIONS}

Television Advertisement is a factor that every marketer should concern as it may urge the youth buying behavior. Therefore marketers should pay their attention and focus on this area in order to generate the sales and drive their business toward the success. Fruit Drink companies should concentrate on the factors which impact youth buying behavior. The
Television advertisement practices are needed to be integrated and well-coordinated with the other marketing activities in which it can deliver a distinctive message to the consumer and ultimately get them to make a purchase. Youth segment think that using celebrity is a good way to remember the product name, to create positive attitude but they do not believe always it will not be true. To attract the youth segment Television Advertisement should be attractive and for that can use beautiful sceneries, interesting letters and attractive people.

\section{REFERENCES}

Akira Ishida, Alias Abdullah, Hajime Kobayashi, Ichizen Matsumura and Toshinobu Matsuda, 'Survey on fresh fruits demand in Tokyo', International Journal of Research in Engineering, IT and Social Sciences. Vol.1, (2).

Alan Resnik \& Bruce L. Stern (1977), 'An Analysis of Information Content in Television Advertising'. Journal of Marketing, Vol. 41, No. 1.

Amin Asadollahi \& Neda Tanha (2011), The Role of Television Advertising and Its Effects on Children. Interdisciplinary Journal of Research in Business. Vol. 1 (9).

Appala Raju, \& P. Sree Devi (2012), 'Means of Advertisement Impact on Consumer Buying Behavior With Reference to Health Drinks in Kuppam' International Journal of Management and Social Sciences Research. Vol. 1 (2).

Central Bank Annual Reports 2012.

Gaurav Bakshi, \& Surender Kumar Gupta (2013), 'Online advertising and its impact on consumer buying behavior'. International Journal of Research in Finance \& Marketing. Vol. 3 (1)

Gerald J. Gorn \& Charles B. Weinberg (1984). The Impact of Comparative Advertising on Perception and Attitude: Some Positive Findings. Journal of Consumer Research, Inc. Vol. 11 (2).

Ghulam Shabbir Khan, Niazi, Javaria Siddiqui, Burhan Ali Shah \& Ahmed Imran Hunjra (2011), 'Effective advertising and its influence on consumer buying behavior' Information Management and Business Review. Vol. 4. (3).

L.W. Turley \& J. Richard Shannon. The impact and effectiveness of advertisements in a sports arena. Journal of services marketing, vol. 14 no. 4 2000, pp. 323-336.

Liu Tianji (2011) 'Analysis on the Factors to Influence the Effectiveness of Television Advertisements' 2011 International Conference on Future Information Technology. Vol. 13.

Lois Biener, Ming Ji, Elizabeth A, Gilpin Alison \& B. Albers (2010). 'The Impact of Emotional Tone, Message, and Broadcast Parameters in Youth Antismoking Advertisements' Journal of Health Communication. Vol.9.

Lokesh Sharma, Archana Singh \& Dr. Parul D. Agarwal (2013). The Impact of T.V. Advertisements on Buying 
Behaviour of Indian Adults: An Empirical Study. Anveshanam- the journal of management. Vol. 2 (1).

M.G.A. Niroshan, S. N. Dissanayake and D.T.K. Bernard (2008). Consumer Preferences of Ready to Drink Fruit Beverages in Sri Lanka Beverage Market. Second Annual Research Forum of SAEA, 2008: Consumer Behavior.

Mark b. Traylor (1981), Comment on "An Experimental Investigation of Comparative Advertising: Impact of Message Appeal, Information Load, and Utility of Product Class". Journal of Marketing Research. Vol. 18.

Marshall Mcluhan (1964) 'Understanding Media' Canada

Moschis (1980), "Social Interaction and Social Structural Determinants in Adolescent Consumer Socialization", in NA - Advances in Consumer Research Volume 07, eds. Jerry C. Olson, Ann Abor, MI : Association for Consumer Research, Pages: 757-759.

Prasanna Kumar \& K. Venkateswara Raju (2013). The Role of Advertising in Consumer Decision Making. IOSR Journal of Business and Management. Vol. 14 (4).
Schiffman, Leon G.; Kanuk, Leslie Lazar Consumer Behavior, $8^{\text {th }}$ edition, Published by Prentice Hall, Upper Saddle River, NJ, 2004

Sujata Khandai \& Bhawna Agrawal (2012) 'Impact of television commercials upon the purchase behavior of urban Indian children' International Journal of Marketing and Technology. Vol. 2. (4).

Swati Bisht (2013). 'Impact of TV advertisement on youth purchase decision - literature review, International Monthly Refereed Journal of Research In Management \& Technology. Vol. 2.

Uditha Liyanage, Profiling the Sri Lankan Consumer (2005)

Vinod Kumar Bishnoi \& Ruchi Sharma (2009) 'The Impact of TV Advertising on Buying Behavior: A Comparative Study of Urban and Rural Teenagers' JK Journal of Management \& Technology. Vol 1 (1). 